\title{
"What is it to be a man?" Rites,
}

\section{hashtags, outrage}

$>\quad$ Lungelo Manona

Department of Media \& Communication, Nelson Mandela University, Port Elizabeth, South Africa

lungelo.manona@mandela.ac.za (preferred pronouns: he/him)

$>\quad$ Andrea Hurst

SARCHI Chair in Identities and Social Cohesion in Africa, Nelson Mandela University, Port Elizabeth, South Africa

andrea.hurst@mandela.ac.za (preferred pronouns: she/her)

\section{ABSTRACT}

This article aims to understand the outrage caused by Inxeba (2017) set within the context of ulwaluko, the Xhosa traditional rite of passage. The scale of the outrage showed deep rejection by many South Africans of the very ideas that the film puts across. This outrage must be understood in relation to the sensitivity of the film's content: masculine identity; the question of what it is to be a man; the multiple interlinked issues of who has power to determine what a Xhosa man is; the justification of heteronormative masculinity; and the construction of multiple masculinities. Assuming that such questions and issues raised by the film cannot be discussed in depth without sufficient contextual knowledge of what the ulwaluko practice involves, the article begins with an account of this practice. Turning to an attempt to understand the outrage caused by the film, it is argued that the most cited reason for this outrage - namely that it challenges the power base of traditional cultural leaders by opening private rites to general public scrutiny - covers over a more pressing concern: that the film depicts an entrenched cultural tradition in a way that subjects its heteronormative ideal of manliness to controversial critique from the perspective of more diverse masculinities.

Keywords: Inxeba (Trengove 2017), masculine identity, heteronormativity, ulwaluko, diverse masculinities. 


\section{Introduction}

With the release of Inxeba (2017), the Xhosa traditional practice of initiating boys into manhood was laid out for public scrutiny. Before many people had seen it, the film was met with vehement resistance and rejection. The controversy first surfaced when screenshots, mostly from the film's trailer on Youtube.com, were shared on social media platforms. From these snippets, many people formed initial opinions, culminating in a legal battle over the film's age classification. Protestors also attempted to bar the film's release in Eastern Cape cinemas. Some reactions were strong, and leading actors received death threats. In the ensuing public debates, many who expressed unhappiness with the film were male members of various Xhosa communities countrywide, especially since the film interrogates the age-old Xhosa tradition of initiation known as ulwaluko. The narrative follows a young traditional caregiver, or ikhankatha, Xolani (Nakhane Touré), as he joins other men of his rural community on an annual journey to the mountains to initiate a group of teenagers into manhood. Many of those who expressed outrage saw the film as an attack on culture, arguing that the film challenges the power base of traditional cultural leaders by opening what are supposed to be private (secret) rites to general public scrutiny. In response, many argued for the protection of the dignity of traditional cultural and community values and beliefs. Before such arguments can be responsibly considered, or discussed in depth, it is essential to elaborate on the film's contextual treatment of the ulwaluko practice.

\section{The rootedness of ulwaluko within African communities}

For the Xhosa nation, ulwaluko - long seen as a tradition that has stood the test of time - is regarded as a sacred and necessary step toward proper or real "manhood"; in fact, many view it as the only culturally recognised path. The discussion to follow briefly considers the roots and rootedness of such practices within African communities, the significance of circumcision in the teaching of manhood, as well as what this collective idea of attained manhood means for those who struggle to fit into its prescripts. This discussion should show why the film has entered dangerous territory, in light of the continued attachment to customs that some have described as archaic or outdated (Ndangam 2008:219).

The traditional rites of passage, communal or individual, continue to form an essential part of the transformation process by which young people in many South African 
communities are formally guided to adulthood (Van Vuuren \& De Jongh 1999:143). This is consistent with the broader African context, where similar rites of passage, as depicted in the film, have existed for hundreds of years. For example, such rites are practised by the Kurya people of Tanzania and Kenya, who belong to the broad category of Bantu speaking groups (Mshana, Wambura, Mwanga, Mosha, Mosha, \& Changalucha 2011:1112). The Kurya share with the Xhosa the centrality of clans to the social organisation and identity of the community. Clan leaders assume the responsibility of being custodians of cultural knowledge and practices. The rituals involved often include a surgical procedure, most notably ritual male circumcision and less commonly female circumcision. Male circumcision is one of the oldest surgical procedures in the world, and has 'spread across the globe over centuries, through both persuasive and coercive means' (Mshana et al. 2011:1111). Within the African context, these reasons usually include cultural and religious identity (Mshana et al. 2011:1111). Further to this, studies from West and Southern Africa have shown that the specific manner in which male circumcision is practised has both social and cultural significance (Mshana et al. 2011:1112). For example, Xhosa people value traditional circumcision more highly than medical circumcision, commonly enforcing this value socially through ridiculing both the uncircumcised and medically circumcised, and even through physical coercion.

A male child must undergo the circumcision rite as a transitional period into manhood, and the expectation thereafter is to become a father. It is therefore the period of preparation for the young male to begin undertaking adult and family responsibilities as a man. It is also the period during which boys are trained in the traditions and customs of their forefathers, in order to assume power within their communities and broader society. "Acting like a man" implies assuming responsibility for knowing the secrets and ways of the tribe or clan (Mshana et al. 2011:1113). Traditional rites of passage foreground the "triadic" connection between the individual, the familial grouping (the clan), and the spiritual. It is accepted that prior to the circumcision activities, clan leaders perform traditional rituals to appease their ancestors and ensure that no harm comes to any of the initiates. To the Kurya, the circumciser/traditional surgeon is selected by the ancestors in order to be acceptable to the clan. A traditional surgeon from the Kurya is quoted thus:

A circumciser is chosen by ancestors [...] he might be sleeping and wakes up to find out that there is blood all over his bed, or he may be walking and pick up the circumcision knifes or he may wake up with a knife on his hand. This is how he recognises that he has been chosen for the task (Mshana et al. 2011:1113).

Modernisation, as well as commercial aspects, have found a way into these rites, since parents (ordinarily the father) not only decide when to circumcise/initiate their 
sons into manhood - depending on their age, physical maturity or their readiness to assume the requisite responsibility - but also must take account of their ability to organise the process and carry all the associated costs. In the absence of parents, relatives are tasked with these responsibilities. Further, sometimes young people decide for themselves when they want to go through the ritual and may then put pressure on their families to make the necessary arrangements (Mshana et al. 2011:1113).

The initiates are expected to eschew fear and pain, leading up to and during the ceremony, and especially when the circumciser/traditional surgeon approaches them and performs the procedure. For the Kurya, "[s] uch show of bravery is rewarded by the initiates receiving money and gifts from their family. Traditional herbs (such as Mwitonkoba) and procaine penicillin forte (PPF) powder are applied to the wound to facilitate healing' (Mshana et al. 2011:1113). Something which might be considered even more particular to this community, is that should an initiate die during the initiation process, the body is not buried but thrown from one bush to another until it decomposes. This is because an initiate's death is interpreted as a sign of misfortune to the clan - in a sense, this can mean that the boys who die are not acceptable to these communities or are not worthy to be considered men at all (Mshana et al. 2011:1114). Typically, at the conclusion of the process a homecoming celebration is held at the home of the initiate. Kurya traditional dance, known as litungu, is organised by the dancing group fetching the initiate from the Kibaga. In this way, these newly initiated men are celebrated and are thereafter deemed adults who would be capable of taking social responsibilities. This of course comes with a variety of expectations such as marriage, taking care of one's family and clan property such as cattle comprising a transformation from child (rishani) to warrior (mura) (Mshana et al. 2011:1114).

Also, within this group, general attitudes towards circumcision indicate that this is a valued practice. Members express the view that circumcision protects males against sexually transmitted infections, such as syphilis and gonorrhoea, and enhances personal hygiene. Beyond this, the view exists that a circumcised young man conforms to tradition and customs. In addition, to the Kurya circumcision shows that a son is ready for marriage - with women reported to have a negative attitude towards uncircumcised men (Mshana et al 2011:1115). It was also pointed out that women who marry uncircumcised men are ridiculed or stigmatised. While social pressure for traditional circumcision is applied through the ridiculing and stigmatisation of uncircumcised males - who are labelled murisya - those circumcised at health facilities are perceived in a similar fashion (Mshana et al 2011:1114). A certain idea of masculinity takes precedence here, where the experience of pain is an important aspect, carrying with it significant symbolism and meaning - the initiates are expected to demonstrate 
the ability to withstand the pain that they experience. This is framed as a demonstration of bravery and courage; important attributes of male adulthood among the Kurya. For this, and other traditionally circumcising communities, the non-expression of pain during traditional circumcision is viewed as a "test" that initiates must undergo and "pass" in order to acquire responsibilities that come with manhood (Mshana et al. 2011:1115).

\section{Circumcision and the teaching of manhood}

In 'Rituals of manhood in South Africa: circumcision at the cutting edge of critical intervention' (1999), Van Vuuren and De Jongh (1999:143) note that traditional circumcision is practised across South Africa by different tribes and it is seen as a rite of passage from boyhood to manhood. For Xhosa speaking people in particular - within whose cultural experience Trengove's film is set - traditional male circumcision has been a custom for generations, particularly in the area today known as the Eastern Cape. Within this context, initiation schools are primarily seen as places where boys are taught life lessons, and medical male circumcision is seen among the Xhosa people as something contra-tradition and a threat to their heritage, even in the face of the high number of deaths that occur during each initiation season. Thus, like those who are deemed to not be "man enough", those who undergo medical circumcision are never accepted, treated and admitted as men within their communities. This is due to the notion that going to a hospital, or other medical facility, is viewed as contamination by something that is completely foreign. This is directly relatable to why Kwanda is initially praised by Xolani for 'coming all the way from Johannesburg, instead of going to a hospital like other city boys' (Trengove 2017).

Among the Xhosa people, collective circumcision was practised in the past, but it has since become an individual affair. The period of seclusion differs among various practicing groupings, but in all cases the re-introduction of novices into conventional society is marked by elaborate celebrations and rituals. In such a context, social pressure to conform plays a major role, thus pressure is likely to be experienced by adolescents. Dingindlela (2014:10) shows, in 'Views of traditionally circumcised Xhosa men towards medical male circumcision', that a majority felt that they could be stigmatised if they fail to conform, even if they were to opt for medical rather than traditional circumcision. This is largely owing to instances of ridiculing and stigmatisation of uncircumcised males or those circumcised in a hospital, and bears testimony to the amount of anxiety that young men face, in the often overwhelming desire to be accepted as men. In this regard, Dingindlela (2014) cites the example that during a 
traditional feast uncircumcised men are not allowed around the area of festivities where food is being prepared or cooked. When they are being given a piece of meat it would be thrown at them and they would be referred to as dogs, as reflected in the isiXhosa saying "inkwenkwe yinja" ('a boy is a dog'). In such cases, it is not uncommon for girls to tell uncircumcised men that they don't date amakhwenkwe (boys/ uncircumcised men).

To Xhosa speaking people initiation is not only about the surgical operation alone - which is but one element - as initiation schools are regarded as sacred places where initiates are prepared for courtship, negotiating marriages and other social responsibilities (Dingindlela 2014:27). In initiation schools, boys are taught "what it means to be a man". This implies that boys learn about the dignity of manhood and how to behave as an adult, and they take instructions about sex, marriage and traditional beliefs. In view of this cultural and educational function, 'Xhosa Traditional leaders have argued that if the custom is changed and medical male circumcision is promoted this (educational part) might be lost and this might alter the custom and its relevance to the Xhosa people of the Eastern Cape and these communities will not tolerate such a cultural shift' (Dingindlela 2014:27).

Dingindlela (2014:28) acknowledges that sometimes in traditional male circumcision young people die, and that the custom is regularly 'on the news for the wrong reasons'. $\mathrm{He}$ adds that government intervention (in the form of legislation for licencing, for example, medical check-ups and age limits) was necessitated by growing concern and media attention directed towards the complications associated with traditional male circumcision.

\section{Initiation practice as collective and social}

In 'Traditional male circumcision: what is its socio-cultural significance among young Xhosa men?' (2009), Feri Gwata speaks of the ritual as carrying deep social and cultural significance. Gwata considers how it is understood primarily as an agent of socialisation, affirming the findings presented through other studies (such as Dingindlela 2014) that pressure from one's family is indeed a major influencing factor in a Xhosa man's decision to undergo traditional circumcision, and that this decision bears particular importance with regard to one's identity. Gwata also notes how respondents stress the importance of the ritual in "becoming a man", but points more to the endurance of pain than to changing one's subsequent behaviour as a marker of such expected transition. This goes some way towards echoing the broader view that male circumcision rituals hold complex significance for the people involved, a factor which 
tends to be overtaken by the biomedical paradigm. More than being simply the removal of all or part of the foreskin (or prepuce), the practice carries layers of meaning as 'a holistic concept with multiple and interconnected dimensions - religious, spiritual, social, biomedical, aesthetic and cultural' (Gwata 2009:4).

In the South African context, circumcision appears to be gaining traction owing to a variety of reasons - ranging from the belief that it enhances sexual pleasure, through claims that it lowers the risk of HIV infection, to reports of the procedure preventing penile and cervical cancer, as well as lowering the risk of urinary tract infection (Gwata 2009:4). This affirms that the ritual is more than just mere superstition or a series of ritualised actions institutionalised over time. Rather, it can be defined as a way in which members of a society communicate values and ways of living through psychological, social and symbolic interactions and teaching. Also, such rituals can be thought of as a means of "inventing" tradition so as to afford a sense of legitimised continuity with the past and a way of experiencing tradition as fixed. Gwata further describes this socialisation as a process by which a person learns the ways of a given society or social group in order to function within it - a vital way of entrenching social norms and imparting cultural knowledge to initiates. The process depicted within the film also speaks to the body being a social construct, in that beyond being a biological reality, the body is often used to convey cultural or religious values. Gwata (2009:9) argues that "the body is not a "given" but a social category with different meanings imposed and developed by every age, and by different sectors of the population'. She goes further to note that the body is viewed by many as the 'foremost of all metaphors', for a society's perception and organisation of itself: 'To that end, male circumcision can be viewed as a physical manifestation of aspects of a society's traditional value system' (Gwata 2009:9). Of even greater relevance to the film is the instance that the ritual is performed collectively. In this way, the permanent body alteration represents a sense of communion and belonging. And so, such expressions of being part of a collective tend to bear particular importance to those who struggle to fit in to the roles that society prescribes for them, an idea that this article explores. Similarly, within Gwata's view social identity has to do with the interrelation between the individual and the group.

\section{Approaching the outrage caused by the film}

The outrage the film caused can be considered as being tantamount to the rejection of the film itself by large segments of South African society. Some registered their disapproval - and others their disgust - by holding pickets or uploading videos of themselves objecting online. To this end, a simple internet search reveals that in the wake of the "Fallist" wave 
that brought with it social movements such as \#RhodesMustFall and \#FeesMustFall, there emerged a \#InxebaMustFall movement, with the use of this hashtag as a way to consolidate the groundswell of commentary and objection to the film. Related social media posts and comments sections gives the idea that the film, much like the characters within its narrative, constituted a disruption or even a disturbance for many South Africans. Many of the complainants bemoaned a perceived European influence and visual-technological encroachment on a cultural issue that many hold as one of the last remaining traditional practices that Xhosa people can claim as their own. One commentator insisted that ulwaluko is part of the last vestiges of African culture (Anon ${ }^{a}$ 2018), thus reflecting on the film as further ideological subjugation. Others registered their dismay saying that they see this film as an insult and a denigration of Xhosa culture for profit. Cultural appropriation was also cited as a reason for the film to be banned - this being in direct reference to Trengove being a white man (Anon ${ }^{\mathrm{b}}$ 2018). Part of the question raised, as to who has the power to determine the nature of masculinity, is the perceived encroachment of modernity on traditional beliefs and communities, and its attendant attitudes and beliefs. This plays out through a process and within a culture that governs the lives of men in many different ways: Modernity is represented by the city and the effect it has on people who leave the rural areas opens up a further debate on class differentiation.

Thus far, public commentators, for example Gqola (2007), have actively participated in a polemic that is primarily about how ulwaluko should or should not be spoken about. The discourse became caught up in the notion that "ulwaluko is something under attack and an entity that, therefore, needs protection and or defence' (Gqola 2007:147). One other important reason for the outrage generated by the film is that it challenges the power base of traditional cultural leaders by opening the ulwaluko rites to general public scrutiny and comment. Trengove's film depicts part of this practice, something that was seen by many people who identify with Xhosa culture and even broader African cultural practice as being offensive, and for some, deeply so.

However, it becomes very clear that the rhetoric of cultural rights and their protection masks a more predominant reason for the outrage provoked by the film, as ulwaluko may be seen as the production and subsequent reproduction of a restrictive kind of (heteronormative) masculinity, especially for those who are forced to remain on the periphery of tradition, acceptance and inclusion. As Aernout Zevenbergen (2009:3) puts it in Spots of a Leopard, to most, "traditions are the answers to questions of purpose and direction. They are the habits, customs, rituals and legends that tell a person who he is, where he can go in life'. However, the same traditions also safeguard the benefits of privilege afforded to some. Thus, the potential for illuminating readings of this film does not lie in the denigration of traditions, rather it is in the experience 
and exploration of more diverse kinds of masculine identity. The hidden and almost denied existence of some is explored, in that the film goes some distance toward illustrating how any initiate suspected of deviating from heterosexual normativity is immediately scorned and excluded. Kwanda is questioned, belittled and scorned in many ways throughout the film. The expectations placed upon him, in the context of an exploration of suppressed homosexuality within an African cultural backdrop, are some of the immediate aspects of the film which have brought to the fore fierce debate fostered by high level of criticism and resistance. The question of what it is to be a man is explored through the character lenses of Xolani, Vija and Kwanda: their varying degrees of fitting in; the pain and fear of same-sex desire in a setting so immersed in a hegemonic idea of what masculinity ought to be.

The film's title speaks directly to a physical wound - as expressed in the act of male circumcision, which constitutes part of this traditional process of initiation into manhood. However, the film is more focused towards uncovering the covert figurative emotional wounding often experienced by many young men - especially those who struggle to, or do not, fit into the various expectations of the traditional narrative. Many of these young men are forced to ask themselves whether identifying as gay or queer makes one less of a man. This has a direct bearing on personal identity, leaving the question open as to whether being a man means one cannot also identify as gay. Further, coupled with the tendency of traditional African societies towards collectivism and communitarianism, those who are uncertain of their gender identity are equally forced to question where they fit into a society. It would perhaps be prudent to note here that such historical structures represent a sense of formal power or social structure. Thus, particularly when rights and resources are unequally allocated among differently socialised actors, they then make the best (or worst) of their situations (Dunbar Moodie \& Ndatshe 1994:274). This results in self-negotiations along the lines of asking what being a man actually entails; what the detrimental attributes and contradictions of this ideal of manhood are; what pressures human beings are exposed to in the quest for this "manhood"; and indeed, who and what they are should they fail to attain such a "prescribed ideal". Indeed, as Thembisa Waetjen (2006:69) articulates in Workers and warriors: Masculinity and the struggle for nation in South Africa, '[t]he discourses of patriarchal traditionalism derive their political potency from the unresolved status of men in modern society and the uncertainty of patriarchal power in the face of social change'.

In addition, the actions and piercing words offered by the character Kwanda - an act of questioning why the people there were even doing what they were doing - in the midst of his initiation, pose a disruption to the institution akin to the one that the film appears to have posed in Xhosa society (and perhaps, even in broader South African 
society). In this regard, in the chapter 'Negotiating the boundaries of masculinity in post-apartheid South Africa' in Men behaving differently: South African men since 1994, Liz Walker (2005) notes that the 1996 Constitution and bill of rights depicts an implicit understanding of sexuality that is premised on a figure of manhood which is as liberal as the constitution itself. She points out that the changes that have taken place in gender-power relations have exacerbated a crisis of masculinity - prompting some men to respond in violent, ruthless and reactionary ways, even while others embraced this new disposition (Walker 2005:161).

\title{
Representing and misrepresenting
}

While many of the expressions of unhappiness regarding the film were centred around anger, characterised by the use of strong and often inflammatory language, some were worded in ways that put across what could be considered to be reasonable arguments. One such instance was an article that appeared in the online publication of the Mail and Guardian newspaper in February 2018. The article, entitled 'Inxeba wounds our cultural practice', begins thus:

\begin{abstract}
A gay love story set in an initiation school was bound to ruffle feathers.
In the days before the opening night of the movie Inxeba (The Wound), the Man and Boy Foundation and the Congress of Traditional Leaders of South Africa (Contralesa), made a last-ditch effort to block the film from being shown - mobilising their members to stage sit-ins until their demands were met (Collison 2018).
\end{abstract}

The article details how, one week before the national release date of the film, a group of about 30 people held a sit-in at the Braamfontein offices of the Commission for the Promotion and Protection of the Rights of Cultural, Religious and Linguistic Communities (CRL Rights Commission), a body established in terms of the South African Constitution with the stated mandate of assisting South Africans with nation building by providing space for each of the cultural, religious and linguistic communities to air grievances and to promote unity amongst diverse communities.

One of the main complaints brought forward by the two groups participating in the protest was 'the misrepresentation of the practice of initiation' (Collison 2018), and that the aim of staging a protest was to have the commission 'block' the screening of the film as they saw it as an 'onslaught on our culture' (Collison 2018). In response to the men's demands the CRL rights commission's chairperson, Thoko MkhwanaziXaluva, said: 
You're swimming upstream here. The Constitution guarantees freedom of expression and does not allow for the banning of a movie. In apartheid days, so many things were banned. People are saying you are opposing the movie because of homophobia. What we need to get is an understanding that this not about gay people, but about misrepresentation of the culture. It is a fact that gay people are everywhere. They have a right to live their lives. It's got nothing to with the objections, I hope (Collison 2018).

Both the Man and Boy Foundation and Contralesa denied that their actions were motivated by homophobia, rather claiming that their opposition was owing to the film misrepresenting initiation schools and 'depicting things that don't [actually] happen there' (Collison 2018). As one of the protesters stated:

Traditional initiation schools are sacred spaces - not a space for sexual activity, regardless of whether it is homosexual sex or not. Others are against Inxeba because of the homosexuality but that argument fuels homophobia, which is quite dangerous. It is fuelling hatred. Our line of argument is not that. Our view is that, even sex between a married couple cannot happen there, because it is a sacred space (Collison 2018).

Another, the Congress of Traditional Leaders of South Africa's Prince Manene Tabane, also stated that the film's gay content 'is not our main thing' (Collison 2018):

If people do that thing, they can do it somewhere else - not within our cultural practice. It doesn't happen in initiation schools. This is ridiculing our cultural practice. We are being embarrassed. The things that are being shown there [are] not what is happening in the mountain. It is disgusting and disrespectful of our cultural practices. People making love in an initiation school is not something we see.

Although these may be viewed as points of some validity, some counter points may be raised. For instance, when the men claim that their main issue is, what they term, misrepresentation of the traditional practice, they are not acknowledging that film is an art form, and the tendency therefore leans toward stories being told from a particular point of view. In this regard, the filmmakers have made no claims on Inxeba's documentary nature, nor have they made any claims of factual accuracy. Furthermore, in response to the statement that the objection is not to homosexual content but rather to sex at the site of the traditional school, which is regarded a sacred space, it should be noted that in the film, none of the intimate activity occurs at sacred places (the filmmakers time and time again emphasise that the characters move some distance away from these spaces before intimate scenes occur), and the initiation school is merely used as a backdrop to the narrative events unfolding. 
Interestingly, there seems to be a parallel between the protest justification and the representations made on various platforms of social media, specifically in the use of words such as "disrespectful", "ridiculing of culture", "embarrassing" and "disgusting", as well as other comments such as "Our intention is not to instigate violence". And statements such as those uttered by protesters, 'We want to communicate that this movie is violating the cultural rights of indigenous communities of South Africa. We will educate people and plead with them not to see the movie because it is explicit and not fit for public consumption' (Collison 2018), and 'misinformation and misrepresentation [which aims] to discredit not only this practice but black African people [as a whole]' (Collison 2018) seem to reoccur across various platforms.

Thereafter, the Congress of Traditional Leaders of South Africa and the Men and Boys Foundation approached the Film and Publications Board (FPB), and petitioned that the film be reclassified from a 16 SNL classification to a no under-18 classification. They also demanded an official disclaimer stating that the film is 'not a true reflection of what happens in initiation schools' (Collison 2018) be enforced. The film was later reclassified - given the same classification as hard-core pornography - effectively banning the film from being shown publicly. This decision was later overturned following legal contestation by the filmmakers.

A second aspect of protestation raised quite sharply across platforms was that of the issue surrounding the mystery and secrecy of the ritual. Many people expressed feelings of being hard-done by; that films like this one reveal things that should remain sacred and mysterious, and that there should be a cultural veil of secrecy respected by anyone who has been through this specific rite of passage. Yet, those protesting Inxeba ignored the fact that this veil of secrecy has long been broken - one has to admit that the film revealed nothing that was not already known in the public domain. For instance, a simple internet search on the subject reveals much more (graphic) detail than the film does. Even popular and revered texts such as Nelson Mandela's 1994 biography, Long Walk to Freedom, reveal more detail as he narrates his personal experience within those pages. Even beyond the book, Madiba can again be seen narrating his initiation experience in a documentary entitled Mandela: Son of Africa, Father of a Nation (1996). No outcry in response to either of these instances is known.

There are further examples of such exposure of the ritual in the public domain. In Lifting the cloak on manhood: coverage of Xhosa male circumcision in the South African press Lilian Ndangam (2008:209) opens with the following quote by Sicelo Fayo: 'In South Africa's liberal and non-racial society, black Africans need to decide whether black traditional customs, such as circumcision - and cultural practices as a whole - remain a critical hallmark to being African'. Here, she makes the point that the post- 
apartheid democratic dispensation in South Africa brought about the possibility of marginalised discourses gaining influence, and that the formation and emergence of new versions of masculinity would form a crucial part of reconstituting post-apartheid South Africa (Ndangam 2008:209). Ndangam further makes the point that initiation rites such as ulwaluko can be seen as spaces in which marginalised masculinities have been, and are being (re)constituted within the new South African context. In this regard, aspects of Black African masculinities continually emerge as sites for the projection, negotiation and renegotiation of post-apartheid socio-political transformation anxieties, insecurities and uncertainties. In order for such changes to happen in earnest, people need to be informed and spaces should be created in which this 'constructive renegotiation' (Ndangam 2008:209) can occur. Thus, media coverage of such cultural practice is not necessarily bad, where such spaces are able to foster understanding and analysis of particular cultural definitions of masculinity (Ndangam 2008:209).

\section{Hashtags and Grahamstown (Makhanda) Festival}

Here, Ndangam makes an example of an exhibition by artists Thembinkosi Goniwe and Churchill Madikida, entitled Initiation as a Rite of Passage, which formed part of the 2004 South African National Arts Festival (NAF) in Grahamstown (Makhanda). The exhibition featured the use of photographs, video and songs to explore the subject of male circumcision and initiation ceremonies (Ndangam 2008:209):

Photographs of young initiates wrapped in white blankets, with their faces painted in white clay and standing next to an initiation hut. A more graphic illustration at the exhibition included a portrait of a naked man with blood around his genitalia. Other aspects of the exhibition included outfits worn by initiates during and after the ceremony, objects used during initiation ceremonies, and artefacts from different parts of Africa where male initiation is practised.

It is worth noting, of course, that such a public display of a rite of passage that is - by most accounts - meant to be kept secret would be a source of some controversy during the festival, and it resulted in media coverage and much-needed public debate about ulwaluko. Of major concern for some was that such a public display of the practice broke the taboo surrounding the secrecy and sanctity of the ritual - a ritual which is supposedly not to be seen by women, children and those who have not been traditionally circumcised. Ndangam (2008:210) notes that in response to this, Xhosa 
traditional leaders felt that the exhibition undermined the symbolic meaning of the rite, while some parents thought it could potentially scare children from participating in the tradition. Ndangam (2008:210) goes on to note that '[b]oth the debate over the NAF exhibition and subsequent coverage are indicative of an ongoing public debate about the practice of initiation by some of South Africa's ethnic groups'. Thus, the discursive representation of ulwaluko in media spaces provides an interesting opportunity to explore the constitution and reinterpretations of masculinity within popular discourse, and in this case, a constructive debate ensued (Ndangam 2008:210).

It becomes of particular interest then that when Inxeba was offered for showing at the same festival in 2018, the reaction was quite different - even resulting in threats of violence and destruction against the festival should the film be shown. In response to this, the National Arts Festival board took the step of holding consultations and discussions with a number of stakeholders and, eventually, the decision was made that the film will not be shown. This is significant in that it shows that, even though there are other representations of ulwaluko available in the public domain - many often more detailed and graphic - this particular representation seemed to solicit a violent rejection and retaliation.

For that matter, after the film's reception, ulwaluko continues to be regularly debated in the media. However, the focus usually falls on press reports detailing initiate deaths and mutilations during the various initiation seasons. These unfortunate occurrences and deaths of young men also put the traditional rite of passage under scrutiny, and serve as the most common frame under which most of the debate on male circumcision now occurs. Yet, these headlines hardly generate as much outrage as the film's proposed showing did.

Through the use of hashtags such as \#Boycottlnxeba, \#NoTolnxeba and \#Burnlnxeba and other social media campaigns, people opposed to the screening of the movie proceeded to call on every "self-respecting" Xhosa man to make their presence felt at cinemas planning on showing the film. By the beginning of 2018, the drive toward building a coercive consensus against the screening of the film was in full swing. As this situation escalated, threats were issued and pickets were held at movie theatres, and the film was subsequently pulled from being screened in the Eastern Cape. Protesting movements had achieved their short term aim, but to what end? What, exactly, is the all-important "manhood" that these groups seem so eager to protect from scrutiny? This approach assumes that there is one way of being a man and one form of masculinity, and public debate is driven to extremes at the altar of cultural propriety. 


\section{Conclusion}

As a way towards looking at how the outrage caused by Inxeba could be understood, this article first elaborated on the cultural context within which the narrative is set, showing that the practice is not unique to the Xhosa of South Africa. However, due consideration was given to why the film's reception was framed in such emotive ways. It raises challenging, interlinked questions concerning deeply ingrained, traditional beliefs concerning what it is to be a man. Notably, the film raises such questions in the context of a strong societal tendency to privilege one form of masculinity, which renders other kinds of masculinity invisible. To this end, Lisa Lindsay and Stephan Meischer (2003:4) define the term masculinity as 'a cluster of norms, values, and behavioural patterns expressing explicit and implicit expectations of how men should act and represent themselves to others'. Put simply, ideological masculinities remain culturally and historically constructed - meaning is continually contested and renegotiated. However, existing power relations still control the frames and lenses of discourse. Thus, because not all versions of masculinity enjoy equal power, privilege and legitimacy in society, certain spaces are continually placed out of the reach of those who do not necessarily conform to certain norms. In this case, masculine identity in South Africa remains almost the exclusive domain of traditional heterosexual maleness - in the process denying the voices and lived experiences of others.

Films such as Inxeba serve, if nothing else, to expose the existence of fertile ground for contestation of ideas, robust debate and conceptual renegotiations. It is worth noting that the overarching importance and value of such films and other forms of art and media representations can be found in their ability to throw the proverbial cat amongst the pigeons, thus sparking further debate. In light of this film, the question arises of where South African society should draw the line between the protection of ingenious cultural rights and the rights of those men who - by virtue of their personal experiences with alienation and rejection - are forced to operate on the margins of such societies. Engendering such debate becomes all the more critical if we remind ourselves that the ontological importance traditionally placed upon ulwaluko still today means that many young men and boys die or are wounded - both metaphorically and physically - in the quest to attain the culturally sanctioned ideal manhood.

\section{Acknowledgements}

This work is based on research supported by the National Research Foundation (NRF) of South Africa (Grant Number: 99188). We acknowledge that opinions, findings and 
conclusions or recommendations expressed in any publication generated by the NRF supported research is that of the authors, and that the NRF accepts no liability whatsoever in this regard.

\section{REFERENCES}

Anon ${ }^{\text {a }}$ 2018. Inxeba's 'Porn' rating was due to public pressure. [O] Available: https://www. thedailyvox.co.za/tag/inxebamustfall Accessed 15 July 2018.

Anon ${ }^{b}$. 2018. John Trengove's latest film, The Wound premiers in Berlin. [O] Available: https://www.youtube.com/watch?v=c51N6wo2urA Accessed 15 July 2018.

Collison, C. 2018. Inxeba wounds our cultural practice. Mail \& Guardian [O] Available: https://mg.co.za/article/2018-02-02-00-inxeba-wounds-our-cultural-practice Accessed 15 July 2018.

Dingindlela, L. 2014. Views of traditionally circumcised Xhosa men towards medical male circumcision. MA dissertation, University of the Witwatersrand, Johannesburg.

Gqola, PD. 2007. A woman cannot marry a boy: rescue, spectacle and transitional Xhosa masculinities, in From boys to men: social constructions of masculinity in contemporary society, edited by T Shefer, K Ratele, A Strabel, N Shabalala \& R Buikema. Lansdowne: UCT Press:145-159.

Gwata, F. 2009. Traditional male circumcision: What is its socio-cultural significance among young Xhosa men? CSSR Working Paper 264(1):1-27.

Lindsay, LA \& Miescher, SF. 2003. Introduction: men and masculinities in modern African history, in Men and Masculinities in Modern African History, edited by LA Lindsay \& SF Miescher. Portsmouth: Heinemann:1-23.

Mandela, N. 1994. Long Walk to Freedom. Macdonald Purnell.

Mshana, G, Wambura, M. Mwanga, Mosha, J. Mosha, F. \& Changalucha, J. 2011. Traditional male circumcision practices among the Kurya of North-eastern Tanzania and implications for national programmes. AIDS Care 23(9):1111-1116.

Dunbar Moodie, T \& Ndatshe, V. 1994. Going for gold: men, mines, and migration. Johannesburg: Witwatersrand University Press. 
Ndangam, LN. 2008. Lifting the cloak on manhood: coverage of Xhosa male circumcision in the South African press, in Masculinities in Contemporary Africa, edited by $\mathrm{E}$ Uchendu. Dakar: CODESRIA:209-228.

Trengove, J (dir). 2017. Inxeba [Film]. Urucu Media.

Van Vuuren, CJ \& De Jongh, M. 1999. Rituals of manhood in South Africa: circumcision at the cutting edge of critical intervention. S.Afr.J.Ethnol., 1999, 22(4):142-156.

Waetjen, T. 2006. Workers and warriors: masculinities and the struggle for nation in South Africa. Urbana and Chicago: University of Illinois Press.

Walker, L. 2005. Negotiating the boundaries of masculinity in post-apartheid South Africa, in Men behaving differently: South African men since 1994, edited by G Reid \& L Walker. Cape Town: Double Storey:161-182.

Zevenbergen, A. 2009. Spots of a Leopard: on being a man. Cape Town: Laughing Leopard. 